\title{
Is pulmonary embolism a common cause of chronic pulmonary hypertension? Limitations of the embolic hypothesis
}

\author{
P. Egermayer*, A.J. Peacock**
}

\begin{abstract}
Is pulmonary embolism a common cause of chronic pulmonary hypertension? Limitations of the embolic hypothesis. P Egermayer, A.J. Peacock. (C)ERS Journals Ltd 2000.

ABSTRACT: The hypothesis that chronic thromboembolic pulmonary hypertension results from unresolved pulmonary embolism has strongly influenced the diagnosis and management of this disease since the 1960s. However, it is nearly impossible to induce chronic pulmonary hypertension in any animal species by means of repeated embolization of thrombotic material. The haemodynamic effects of thrombotic pulmonary embolism of different degrees of magnitude have also been studied in humans and there is little to suggest that chronic pulmonary hypertension is a likely long term outcome. Furthermore many conditions which predispose to venous thromboembolism do not appear to cause thromboembolic pulmonary hypertension. Other arteriopathic and atherosclerotic risk factors, are found in patients with chronic thromboembolic pulmonary hypertension, but not in those with venous thrombosis, suggesting that these may be unrelated conditions.

Thrombosis in situ of the pulmonary arteries is common in severe pulmonary hypertension of any cause. Such thrombosis cannot usually be distinguished from pulmonary embolism. It is hypothesized that in situ thrombosis and pulmonary arteriopathy are common causes of vascular occlusion which is usually diagnosed as "chronic thromboembolic pulmonary hypertension" and that venous thromboembolism is unlikely to be a common cause of chronic pulmonary hypertension. It is further hypothesized that pulmonary embolism is seldom the sole cause of "chronic thromboembolic pulmonary hypertension".

Eur Respir J 2000; 15: 440-448.
\end{abstract}

*The Canterbury Respiratory Research Group, Christchurch School of Medicine, Christchurch, New Zealand. ** Scottish Pulmonary Vascular Unit, Dept of Respiratory Medicine, Western Infirmary, Glasgow, G11 6NT, UK.

Correspondence: P. Egermayer, Canterbury Respiratory Research Group, PO Box 4015, Christchurch, New Zealand. Fax: 6433641184

Keywords: Chronic thromboembolic pulmonary hypertension pathophysiology

pulmonary arteriopathy pulmonary atherosclerosis pulmonary embolism pulmonary hypertension

Received: May 181999

Accepted after revision November 291999
The autopsy findings of pulmonary hypertension $(\mathrm{PH})$, right ventricular hypertrophy, and right heart failure have been recognized by pathologists since the turn of the century [1]. PH was initially regarded as being caused by primary pathological changes in the pulmonary vessels [2]. In 1953 Owen et al. [3] were among the first to suggest that $\mathrm{PH}$ leading to oedematous right heart failure could be caused by multiple silent pulmonary emboli [3]. Subsequent commentators have frequently endorsed this view, however, many were puzzled by the fact that the emboli resulting in heart failure were usually asymptomatic $[4,5]$. Major occlusion of the pulmonary arteries in association with chronic $\mathrm{PH}$ is estimated to occur in between $0.1-0.4 \%$ of autopsies $[6,7]$. By comparison evidence of recent or old pulmonary embolism (PE) may be found in between $60-90 \%$ of all autopsy cases [8].

In modern terminology the disease entity "chronic thromboembolic PH" (CTEPH) refers to PH in which there is occlusion of major pulmonary arteries. Most textbooks and recent reviews consider this occlusion to be primarily or solely the result of venous thromboembolism e.g.

For editorial comments see page 435
"CTEPH is the result of single or recurrent pulmonary emboli arising from sites of venous thrombosis" [9]. The term "chronic PE" is also frequently employed as a synonym for CTEPH although the more descriptive term "chronic major vessel thromboembolic $\mathrm{PH}^{\prime}$ may be preferable, provided it is understood that the term "thromboembolism" may also include cases of pulmonary artery thrombosis.

A great deal of confusion in this area of medicine derives from historical terminology, particularly with regard to the terms "primary" and "secondary" PH. In the past "primary $\mathrm{PH}$ " has been regarded as a distinct pathological entity characterized by plexiform arteriopathy $[10,11]$. However, more recently primary $\mathrm{PH}$ has come to be regarded as a diagnosis of exclusion, and the term "unexplained $\mathrm{PH}$ " would be more appropriate. It has become clear that plexiform arteriopathy is not specific to any specific category of $\mathrm{PH}$, but may be observed in most varieties of severe PH regardless of cause, and also in sheep with PH caused by the creation of vascular shunts leading to increased blood flow through the lungs $[12,13]$. Identifying "causality" is often a matter of opinion, and many authors continue to refer to "primary $\mathrm{PH}^{\text {" occurring in }}$ association with anorexient use and acquired immune deficiency syndrome (AIDS). Similarly, in paediatric patients 
the presence of an alternative cause of pulmonary vascular occlusion, such as disseminated fibromuscular dysplasia, may not prevent recurrent silent PE from being invoked as the possible cause of chronic PH [14]. Most "secondary" forms of severe chronic $\mathrm{PH}$ are clinically and pathologically indistinguishable from primary $\mathrm{PH}$. In the discussion which follows, whenever possible the authors will avoid the terms "primary" and "secondary", in favour of the more neutral term "chronic PH".

There are no reliable clinical criteria to distinguish CTEPH from PH of other causes [15]. Histological differentiation between in situ pulmonary artery thrombosis and occlusions caused by thrombotic material of embolic origin is also difficult if not impossible [5, 16-21].

The purpose of the present discussion is to examine clinical and experimental evidence which may help to answer the question: "Is PE a common cause of chronic PH?" The authors will attempt to arrive at a conclusion by examining the pulmonary haemodynamic effects of different types of PE. The authors will also suggest hypothetical alternative pathophysiological mechanisms that might result in CTEPH, and they will try to establish whether the proximal occlusive lesions of CTEPH are always caused by acute PE, or whether they are generally a result of more gradual hypertensive pathological changes affecting the pulmonary arteries.

\section{Does a single major episode of acute pulmonary embolism cause chronic pulmonary hypertension?}

Major PE causes elevation of pulmonary artery pressure, which cannot be entirely the result of mechanical occlusion of pulmonary arteries, or obliteration of the vascular bed, since ligation of pulmonary arteries or pneumonectomy does not cause similar elevations of arterial pressure [22]. In the acute situation, $>70 \%$ of the pulmonary vascular bed must be occluded before changes in resting pulmonary artery pressure are observed [20]. However, it is likely that such changes would be more readily detected during exercise. Humoral factors, particularly 5-hydroxytryptamine, probably contribute to $\mathrm{PH}$ following PE [23-25].

Several studies involving serial pulmonary arteriography and serial lung scans have demonstrated that thrombotic PE often resolves within a matter of days and resolution is usually complete within weeks [26-29]. In these studies 60 patients were followed who did not receive anticoagulant therapy because of contraindications or because they were treated solely by ligation of the inferior vena cava. In this group the rate of resolution was similar, and in some cases more rapid, than the rate observed in the heparin treated patients. The rate of resolution of PE in situ was not influenced by anticoagulant treatment over 6 months in a recent randomized controlled trial [30]. The beneficial effects of heparin in the treatment of PE relate to prevention of recurrence and not to any thrombolytic properties. Consequently the authors consider the suggestion that CTEPH might result from the persistence of PE in patients in whom anticoagulant therapy has been inappropriately withheld to be somewhat unlikely.

It has also been postulated that some cases of acute PE progress to CTEPH because of a failure of fibrinolysis, but defects in fibrinolysis have seldom been demonstrated among patients with CTEPH $[31,32]$. Long term follow- up of patients with acute PE has usually failed to identify any who proceed to CTEPH [33-36]. Cases of acute PE which apparently resulted in CTEPH have been reported, adding to the impression that this is a well established phenomenon. But these were almost all patients in whom the pulmonary artery pressure measured at the time of the acute event was in excess of $40 \mathrm{mmHg}[37,38]$. It has subsequently been established that the normal right ventricle is unable to generate pressures of this magnitude acutely, so these must mostly have been patients who had $\mathrm{PH}$ prior to the PE in question [39]. Previous PE might explain this, but many other causes are also possible.

REMY-JARDIN et al. [40] studied the evolution of acute massive PE in 62 patients over the course of a year using spiral computed tomography (CT) angiography. This allowed visualization of smaller arteries distal to major occlusions, which is usually not possible with standard pulmonary angiography. They found complete resolution in 30 patients $(48 \%)$. In a further 24 patients with more extensive vascular occlusion at the time of diagnosis, there was incomplete resolution leading to $>50 \%$ narrowing of the pulmonary arteries, and the development of chronic $\mathrm{PH}$ in five cases. The patients who developed chronic PH all had chronic arteriopathic changes at the time of initial presentation. Another eight patients who had newly developed features of "chronic PE" at followup did not have echocardiographic evidence of chronic $\mathrm{PH}$. Using this novel and apparently highly sensitive investigational technique these authors have demonstrated that "chronic PE" need not necessarily be synonymous with chronic $\mathrm{PH}$.

Nonresolution of clinically suspected massive acute PE had previously been reported in three young female patients who were followed for up to $7 \mathrm{yrs}$ [41]. In two of these cases the pulmonary artery pressure at rest and following exercise was normal at follow-up. In the third case the resting pressure at follow-up was the same as at baseline, but the post-exercise mean pulmonary artery pressure was elevated to $45 \mathrm{mmHg}$, however an exercise test had not been performed at baseline. These cases confirm the impression that persisting acute major occlusion of the pulmonary arteries does not usually by itself account for the development of chronic $\mathrm{PH}$, other pre-existing factors are generally involved. Furthermore, acute PE is often diagnosed, and possibly misdiagnosed, in patients who have pre-existing pulmonary artery pathology.

Dogs have been the most frequent subjects of experimental PE. Older dogs are susceptible to spontaneous thromboembolic disease, particularly when there is comorbidity [42]. In this species, impaction of large thrombi in the pulmonary arteries causes hypoxaemia, but no noticeable cardiovascular effects and only very minor and transient increases in pulmonary artery pressure [43]. It has been suggested that dogs may be poor experimental models for CTEPH due to a more active fibrinolytic pathway than humans. While the evidence for this hypothesis has been questioned, it cannot be entirely discounted [44]. CTEPH cannot be induced in dogs by large thrombi, unless the dogs have been treated with tranexamic acid to inhibit fibrinolysis [45].

In summary, the authors are not aware of any convincing evidence that a single major PE progresses to CTEPH in humans or in other species. 


\section{Do recurrent episodes of major pulmonary embolism cause chronic pulmonary hypertension?}

Recurrent PE is a frequent cause of death in people with pre-existing severe cardiovascular impairment. PE is notoriously difficult to diagnose, and recurrent $\mathrm{PE}$ even more so. Most patients with severe CTEPH have episodic dyspnoea, and this often raises the possibility of PE. However when such patients have previously had lung scans there are usually no scintigraphic changes to support a diagnosis of recurrence [46].

A literature search of MEDLINE and EMBASE in February 1999 using the subject headings "thrombophlebitis" and "PE", and the text words "recurrent" or "recurrence", and "PH" failed to reveal any cases in which objectively diagnosed recurrent deep venous thrombosis or $\mathrm{PE}$ resulted in later chronic $\mathrm{PH}$, except in patients with antiphospholipid antibodies, or other diseases known to lead to PH independently of venous thromboembolism. However, it was common for authors to assume that observed pulmonary artery occlusions were the result of undocumented previous silent venous thromboembolism. Absence of proof is not proof of absence, but this negative result at least serves to emphasize the rarity of this sequence of events. Nevertheless, from general reading, the authors are aware of six cases of recurrent deep venous thrombosis which occurred in patients who later developed $\mathrm{PH}$ which these literature searches did not discover. Curiously, all six cases involved upper limb thrombosis, which is relatively rare [47-52]. The authors are unable to account for this apparent association.

It is virtually impossible to induce CTEPH in dogs by means of repeated embolism of thrombotic material [53]. However, occlusion of $\geq 80 \%$ of the pulmonary vascular bed with inert materials such as lead, may induce $\mathrm{PH}$ in the animals that survive [54]. When the contralateral pulmonary artery was ligated, and autologous thrombi were subsequently embolized, more significant acute elevations of pulmonary artery pressure were observed in dogs. However, it was still not possible to cause chronic $\mathrm{PH}$ by repeated injections over a period of 4 months [55]. However, in dogs treated with tranexamic acid to inhibit fibrinolysis, injected autologous venous thrombi persist in the pulmonary circulation for up to one yr, and repeated injections of this material may elevate the resting pulmonary artery pressure to a level of $\sim 35 \mathrm{mmHg}$ over a period of 30 days [56].

It is concluded that recurrent major PE could cause chronic $\mathrm{PH}$ in some individuals if the cumulative thrombotic load were sufficient and if the episodes were closely spaced. However, in this situation survival is relatively unlikely. Consequently this is unlikely to be a common cause of CTEPH.

\section{Does "miliary pulmonary embolism" cause pulmonary hypertension?}

"Miliary PE" refers to the passage to the lungs of large amounts of material which is mostly not macroscopically visible. Nonthrombotic miliary PE as a result of Schistosomiasis and Dilofilariasis is believed to affect millions, particularly in third world countries. However, in addition to occluding the microvasculature of the lungs, both the eggs of Schistosoma mansoni and filarial worms cause an intense inflammatory reaction with fibrosis of the pulmonary arterioles [57]. A similar vascular reaction, with granulomatous arteritis resulting in $\mathrm{PH}$, is described following the intravenous injection of crushed pentazocine tablets intended for oral use [58]. Miliary tumour emboli are another relatively common cause of right heart failure, since $2 \%$ of patients dying of breast cancer have these findings $[59,60]$. Lacking specific fibrinolytic mechanisms of removal, tumour emboli generally persist longer in the pulmonary circulation than thrombotic emboli [61]. Lycopodium spores have been injected into several animal species and these jagged objects cause more endothelial damage and greater elevations of pulmonary artery pressure than similar sized smooth latex microspheres [62].

When individuals with $\mathrm{PH}$ and right heart failure do not have any visible evidence of deep venous thrombosis, "miliary PE" has frequently been invoked as a possible cause, but this is considered by some to be biologically implausible [63]. When miliary emboli consisting of bland substances find their way into the lungs, adverse effects are extremely rare. For example, when a lung scan is performed, radiolabelled particles of albumin or other microspheres of between $8-50 \mu \mathrm{m}$ in size are injected, so as to occlude between $1-5 \%$ of the pulmonary vasculature. These particles are removed into the lymphatic system in the course of 8-24 h. This procedure is remarkably safe, in the 40 yrs during which it has been employed there have been no reports of chronic PH [64]. Miliary thrombotic embolism also seems to be a relatively benign event. Prolonged asymptomatic microembolism was detected by Doppler ultrasound in most patients undergoing hip or knee arthroplasty, and there were not apparent adverse effects [65].

Up to 76 injections of finely divided thrombi were required to induce even mild PH in rabbits, and severe $\mathrm{PH}$ was not observed [66]. Persisting PH could also not be induced in dogs despite injection of up to $15 \mathrm{~g}$ of copolymer granules, $35-300 \mathrm{~mm}$ in size, over a period of months [67].

\section{Chronic pulmonary hypertension in animals}

Chronic $\mathrm{PH}$ is observed in many animal species. Examples include rats [68], poultry $[69,70]$, cattle $[71,72]$, pigs [73] and horses [74]. Many stimuli that provoke PH in man, such as altitude, hypoxia, parasitic infections, patent ductus arteriosus, endotoxins, anorexient and other drugs have also been shown to provoke similar responses in several other mammalian species, suggesting more interspecies similarities than differences [75]. The fact that chronic PH was not provoked by repeated injections of thrombotic material in any of the animal species previously discussed, is indirect evidence that such a mechanism may also not be operative in humans.

In contrast, occlusion of the pulmonary arteries of piglets by coil embolization, produced a condition which appeared to be histologically and physiologically very similar to CTEPH in humans, but only when tissue adhesive was also applied to the embolization sites. The postoperative responses of the piglets to thrombendartectomy, including reperfusion oedema, also closely resembled the human responses to such surgery [76]. This further confirms the impression that vascular injury much more extensive than that usually caused by embolization with 
bland thrombus is required to provoke CTEPH in both animals and humans.

\section{Are venous thromboembolism and chronic thromboembolic pulmonary hypertension related conditions?}

Venous thromboembolism is common in populations with a high prevalence of Factor V Leiden and other types of thrombophilia, but such thrombophilia is not unduly prevalent among those with CTEPH [77]. However, 10\% of patients with CTEPH have antiphospholipid antibodies $[78,79]$. Antiphospholipid antibodies are a cause of both venous and arterial thrombosis, including thrombosis of the pulmonary arteries [80]. Plasma lipoprotein (a) levels, a risk factor for atherosclerosis but not for venous thrombosis [81], have also been found to be elevated in patients with CTEPH [82]. Protein S deficiency, which is also more of a risk factor for arterial than for venous thrombosis [83], has recently been found to be associated with CTEPH [84]. Oral contraceptives and oestrogens are considered to be risk factors for venous thrombosis but not for chronic pulmonary hypertension [85]. Venous thromboembolism is more common among the elderly, while CTEPH often affects younger adults. Patients with CTEPH generally present without having had any signs or symptoms of venous thromboembolism [6]. The PH in patients with CTEPH is progressive, even in the absence of documented recurrence of PE [86]. Following successful surgical treatment of CTEPH, over 400 patients have been followed for periods of up to 18 yrs with subsequent detection of PE or deep venous thrombosis in only three cases $(0.75 \%)$ [6]. This is in marked contrast to venous thromboembolism where early recurrence rates in patients during anticoagulant therapy are often between 10-20\% [87]. This is despite the fact that the group with operated CTEPH all have the additional risk factor of major surgery. By comparison, the continuing risk for PE among patients with previously normal pulmonary angiograms, is $1.6 \%$ over the following year [88]. Patients undergoing surgery for CTEPH also commonly have filters placed in the inferior vena cava. These filters protect against recurrence of venous thromboembolism, but there is nevertheless a recurrence rate of $\sim 3 \%$ following use of these devices in patients with venous thromboembolism, which contrasts with the lower rate of subsequent PE and deep venous thrombosis when these filters are used in those undergoing surgery for CTEPH $[89,90]$.

These considerations prompt the authors to believe that CTEPH and venous thromboembolism are usually separate and unrelated conditions.

\section{Can nonembolic mechanisms be involved in the pathogenesis of chronic thromboembolic pulmonary hypertension?}

The perceived aetiology of a disease may be important in influencing choice of therapy, for example, if clinicians believe that recurrent episodes of asymptomatic deep venous thrombosis are causing CTEPH they may decide to insert an inferior vena caval filter to prevent such episodes. Failure to detect deep venous thrombosis may be ascribed to the fact that the thrombus has already embolized. Conversely, if deep venous thrombosis is not regarded as a prob- lem in this situation, there would appear to be less reason to employ this type of invasive therapeutic intervention.

In CTEPH, as in other kinds of chronic PH, a fibroproliferative process of vacular remodelling occurs in the terminal arterioles, and is largely responsible for increased vascular resistance. Since the remodelling process commonly affects arteries distal to the site of arterial occlusion, it cannot be entirely attributed to a pressure effect [91, 92].

Recently the potential importance of arteritis and thrombosis in situ have been proposed as causes of CTEPH [93]. Study of allograft transplants shows that physical trauma, viral infection and other vascular insults commonly result in atherosclerosis [94]. PE could represent one form of insult since it has been shown that PE may sometimes evolve over a period of months into arterial thickenings which closely resemble atherosclerotic plaques, and which contain platelet antigens $[95,96]$. Thrombosis is often associated with these plaques [97]. A similar pulmonary atherosclerosis has been observed in rabbits following embolization of bone marrow [98]. The pulmonary arteries examined by angioscopy in CTEPH commonly show evidence of atheroma, (W. Auger, University of California, San Diego, USA, personal communication, 1996), and atherosclerosis is commonly found at post mortem in all forms of PH [99]. As previously mentioned, plasma levels of apolipoprotein (a), a risk factor for atherosclerosis, are elevated in patients with CTEPH [82]. Markers of endothelial trauma or dysfunction, such as endothelins, regularly observed in primary $\mathrm{PH}$, are also found in cases of acute PE [100]. The relative importance of these phenomena in the aetiopathology of CTEPH is unstudied.

It has been observed that $\mathrm{PH}$ is more likely following partial vascular occlusions of pulmonary artery segments than following complete occlusions, suggesting that vasoactive substances produced by turbulent flow may be involved in the pathophysiology [101]. Interaction of platelets with arteriosclerotic plaques also leads to the release of vasoactive substances [75].

Based on these observations it is concluded that many kinds of insult to the endothelium of the pulmonary arteries may initiate a sequence of events which leads to atherosclerosis, remodelling, and CTEPH. Numerous influences such as hypoxia, endogenous vasoconstrictors, and inflammatory cytokines could help to sustain this process [75]. PE could be one such traumatic influence resulting in endothelial damage, but other influences may be more prevalent and more important. Pulmonary vascular responses to insult are often rather stereotyped. The causes of chronic PH are usually multifactorial and idiosyncratic. A single cause and effect model, such as the embolic hypothesis is very unlikely to fully explain most cases. Uncritical acceptance of such a model is likely to be a barrier to further progress. Available evidence (or more precisely lack of evidence) suggests that physical occlusion of pulmonary arteries by embolic mass may be a relatively unlikely cause of CTEPH. Persistance of embolic occlusion for weeks or months could possibly cause chronic $\mathrm{PH}$, but such persistance remains to be adequately demonstrated.

\section{The role of pulmonary endarterectomy}

Any theory of the aetiology of CTEPH must account for the beneficial effects of pulmonary thrombendarterectomy, 
an operation sometimes misleadingly referred to as "delayed embolectomy". Thrombendartectomy is a procedure which is also employed to remove atheroma in the carotid, femoral, renal, coronary, and other large arteries, however, in these locations embolism is seldom postulated as a cause. The obstructing lesions in CTEPH are not fibrin thrombi, but intimal plaques, together with masses of organized material which histologically are very similar to advanced partially recanalized atheroma [102].

To date only $\sim 1,500$ pulmonary thrombendartectomy operations have been performed worldwide [103]. Consequently few clinicians outside of two or three specialized centres will have any significant personal experience with the effects of the procedure. The reader is referred to a recent editorial on this subject, which may dispel some common misconceptions [103]. The removal of visible thrombus is largely incidental to the operation of pulmonary thrombendartectomy. In the majority of patients no free thrombus is present and initial direct examination of the pulmonary vascular bed may appear to be normal.

Vascular obstruction in CTEPH is seldom "localized". In a series of 400 cases, "localized" disease, limited to only one pulmonary artery, was found in only 11 patients $(3 \%)$ and paradoxically carried a much poorer surgical prognosis than the usual more generalized involvement [92]. Surgical success is dependent on complete bilateral endarterectomy of the entire pulmonary tree [103]. Virtually all patients with severe $\mathrm{PH}$, regardless of cause, have generalized arteriopathic changes. These are often poorly appreciated during conventional angiography which visualises only third order segmental vessels, leaving 25-26 divisions of the pulmonary arteries before the capillary bed which are not shown [63].

Although proximal occlusion of the pulmonary arteries (main, lobar or segmental) is the defining feature of CTEPH, in the words of FEDULLO et al. [6] "...it is becoming increasingly clear that hypertensive changes in the small vessels of the remainder of the pulmonary vascular bed have a major influence on its natural history." The histopathological findings in the small pulmonary arteries of patients with CTEPH cannot be distinguished from those in primary $\mathrm{PH}$ [92]. For unknown reasons improving the flow of blood through the pulmonary arteries by thromboendarterectomy, often has a beneficial effect in this condition. From this it may be inferred that extensive proximal occlusion is in some way contributing to the pathophysiology, but this does not establish PE as the cause of the occlusion.

It is widely accepted that chronic $\mathrm{PH}$ is an insidious disease with a long asymptomatic "honeymoon period". There is no doubt that, as with thrombendartectomy performed at other sites, removal of large obstructive lesions in the pulmonary arteries has short and medium term beneficial haemodynamic effects in many cases. However, when follow-up studies of more than a few years become available, it is possible that, after another long honeymoon period, the $\mathrm{PH}$, and possibly the vascular occlusions, may recur in cases where the causative influences persist. Approximately $5 \%$ of patients who have undergone pulmonary thrombendartectomy in San Diego, CA, USA, have suffered a relapse into severe $\mathrm{PH}$ after an interval of months or years [104].
Can embolic occlusion of the pulmonary arteries be distinguished from in situ pulmonary thrombosis?

Thrombosis of the pulmonary arteries is a very common complication of many varieties of PH [105]. For example, CALVERLY et al. [106] found that $\sim 50 \%$ of patients with cor pulmonale due to respiratory failure had pulmonary artery thrombosis at post mortem. These authors pointed out that what their pathologists described as pulmonary artery thrombosis could not have been distinguished ante mortem from PE. PRESTI et al. [107] observed chronic massive pulmonary artery thrombosis in patients with lung disease, and found that it was invariably located on the side of the most serious disease, implying retrograde propagation from peripheral to major arteries in diseased lungs. In this series of over 7,700 post mortems, the incidence of "chronic massive thrombosis" of the pulmonary arteries was $0.1 \%$. Since this is the figure given for CTEPH in other series, it appears that these terms were being used interchangeably in this study [108] As previously discussed, chronic pulmonary artery thrombosis cannot be distinguished histologically from chronic embolization, consequently other authors have also used these terms interchangeably without making assumptions as to causation [109]. Fibrinopeptide levels are elevated in patients with chronic $\mathrm{PH}$, indicating ongoing pulmonary vascular thrombosis, but levels of platelet proteins and fibrinopeptides do not allow patients who are classified as having CTEPH to be differentiated from those with primary PH [108-110]. Complete occlusion of central pulmonary arteries may also be observed, seeming as an incidental finding, apparently without important haemodynamic effects, in some cases of "primary pulmonary hypertension" [111]. PH of any cause predisposes to thrombosis which, in some but not all cases, may further elevate the pulmonary artery pressure $[10,19,112]$.

The imaging techniques which are used to detect PE can demonstrate occlusion of pulmonary arteries, but are not capable of distinguishing the cause. Most clinicians are well aware that PE is common, and that the presentation is often very nonspecific or asymptomatic. Consequently, regardless of clinical findings, patients with chronic PH who have ventilation perfusion mismatch on a lung scan or arterial occlusion at pulmonary angiography, are usually diagnosed as having recurrent PE. But these arteriographic changes are sometimes found to be due to agenesis, arteritis, sarcoma, fibrosis, tumour embolism, or thrombosis of the pulmonary artery $[113,115]$. Patients with proximal vascular occlusion and $\mathrm{PH}$ due to fibrosing mediastinitis also have clinical presentation, scintigraphic, angiographic and right heart catheterization findings which are indistinguishable from those of patients with CTEPH [116]. There are many nonembolic causes of ventilation perfusion mismatch in patients with CTEPH [117]. These alternative diagnoses are often only established at post mortem or at the time of attempted surgery. In up to $30 \%$ of cases in which alternative specific investigations are performed, an angiographic diagnosis of thromboembolic occlusion may prove to be either false positive or false negative [118].

Anticoagulants are often used in cases of CTEPH in the expectation of reducing the probability of recurrent deep venous thrombosis. However, response to anticoagulant therapy does not necessarily imply that venous 
thromboembolism is the cause of CTEPH, since other varieties of $\mathrm{PH}$ also respond to anticoagulant therapy [112119]. The mechanism of benefit in these cases remains speculative, but since primary $\mathrm{PH}$ is not thought to be a condition related to venous thromboembolism, it is reasonable to assume that anticoagulants may have some direct beneficial effects on the pulmonary vasculature in these cases, such as the prevention of in situ thrombosis.

\section{Hypothesis}

It is hypothesized that in most cases, CTEPH is a primary arteriopathy with secondary local thrombosis.

\section{Testing the hypothesis}

This could be performed by attempting to induce chronic pulmonary hypertension in animal species by means of different kinds of vascular trauma and comparing the effects with those of experimental thrombotic pulmonary emboli. It would also be interesting to induce changes by either method, and then submit the animals for subsequent blinded ante mortem and post mortem diagnosis. In regions where Schistosomiasis is endemic, the arteriopathic hypothesis of aetiology would predict a high incidence of angiographic and scintigraphic changes consistent with chronic thromboembolic pulmonary hypertension, and post mortem findings of occluded major pulmonary arteries. Larger long term follow-up studies of patients with well diagnosed pulmonary embolism, in whom other causes of chronic pulmonary hypertension have been excluded, could also be performed to see if any progressed to chronic pulmonary hypertension.

\footnotetext{
Acknowledgements. The authors wish to thank G.I. Town for helpful suggestions concerning the manuscript.
}

\section{References}

1. Kanemoto N, Constant J. Present status of primary pulmonary hypertension. Tokai J Exp Clin Med 1989; 14: 257-280.

2. Editorial. Recurrent pulmonary embolism and cor pulmonale. N Engl J Med 1967; 276: 1261-1262.

3. Owen WR, Thomas WA, Castleman B, Bland EF. Unrecognised emboli to the lungs with subsequent cor pulmonale. N Engl J Med 1953; 249: 919-926.

4. Davidson PH, Armitage GH, McIlveen DJS. Chronic cor pulmonale due to silent pulmonary embolism. Lancet 1956; 2: 224-226.

5. Goodwin JF, Harrison CV, Wilcken DEL. Obliterative pulmonary hypertension and thrombo-embolism. BMJ 1963; 1: 701-711.

6. Fedullo PF, Auger WR, Channick RN, Moser KM, Jamieson SW. Chronic thromboembolic pulmonary hypertension. Clin Chest Med 1995; 16: 353-374.

7. Widimsky J. The relation between acute embolism and thromboembolic pulmonary hypertension. Vnitrni Lekarstvi 1990; 36: 503-507.

8. Egermayer P, Town GI. The clinical significance of pul- monary embolism: uncertainties and implications for treatment - a debate. J Intern Med 1997; 241: 5-10.

9. Moser KM, Auger WR, Fedullo PF. Chronic major-vessel thromboembolic pulmonary hypertension. Circulation 1990; 81: 1735-1743.

10. Wagenwoort CA. Primary pulmonary hypertension: pathology. In: Peacock AJ, ed. Pulmonary Circulation A Handbook for Clinicians, London, UK, Chapman \& Hall Medical, 1996; pp. 325-338.

11. Harris $\mathrm{P}$, Heath D. The human pulmonary circulation. Its form and function in health and disease. Edinburgh, UK, Churchill Livingstone, 1986; pp. 403-413.

12. Cool CD, Kennedy D, Voelkel NF, Tuder RM. Pathogenesis and evolution of plexiform lesions in pulmonary hypertension associated with sceleroderma and human immunodeficiency virus infection. Hum Pathol 1997; 28: 434-442.

13. Schnader J, Schloo BL, Anderson W, Stephenson LW, Fishman AP. Chronic pulmonary hypertension in sheep: temporal progression of lesions. J Surg Res 1996; 62: 243-250.

14. Fukuhara H, Kitayama H, Yokoyama T, Shirotani H. Thromboembolic pulmonary hypertension due to disseminated fibromuscular dysplasia. Ped Cardiol 1996; 17: 340-345.

15. Presbitero P, Chiotti D, Brusca A. Differences in patients with chronic pulmonary embolism and primary pulmonary hypertension. G Ital Cardiol 1988; 18: 39-49.

16. Whittaker W, Heath D. Idiopathic pulmonary hypertension: etiology, pathogenesis, diagnosis and treatment. Prog Cardiovasc Dis 1959; 1: 380-386.

17. Reid L, Anderson G, Simon G. Comparison of primary and thromboembolic pulmonary hypertension. Thorax 1972; 27: 263-264.

18. Wagenvoort CA. Morphological substrate for the reversibility and irreversibility of pulmonary hypertension. Eur Heart J 1988; 9 (Suppl. J): 7-12.

19. Wagenwoort CA, Mulder PGH. Thrombotic lesions in primary plexogenic arteriopathy. Similar pathogenesis or complication? Chest 1993; 103: 844-849.

20. Wagenvoort CA. Pathology of pulmonary thromboembolism. Chest 1995; 107: 10S-17S.

21. Viner SM, Bagg BR, Auger WG, Ford GT. The management of pulmonary hypertension secondary to chronic thromboembolic disease. Prog Cardiovasc Dis 1994; XXXVII: 79-92.

22. Sabiston DC, Durham NC, Wagner HN. The pathophysiology of pulmonary embolism: relationship to accurate diagnosis and choice of therapy. $J$ Thorac Cardiovasc Surg 1965; 50: 339-356.

23. Hamilton WM, Nemir P. The humoral factor in pulmonary embolism. Arch Surg 1972; 105: 593-598.

24. Smith G, Smith AN. The role of serotonin in experimental pulmonary embolism. Surg Gynecol Obstet 1955; 101: 691-699.

25. Gurewich V, Cohen ML, Thomas DP. Humoral factors in massive pulmonary embolism: an experimental study. $\mathrm{Am}$ Heart J 1968; 76: 784-791.

26. Tow DE, Wagner HN. Recovery of pulmonary arterial blood flow in patients with pulmonary embolism. $N$ Engl J Med 1969; 280: 1195-1199.

27. Secker-Walker RH, Jackson JA, Goodwin J. Resolution of pulmonary embolism. BMJ 1970; 4: 135-139.

28. Fred HL, Axelrad MA, Lewis JM, Alexander JK. Rapid resolution of pulmonary thromboemboli in man. An angiographic study. JAMA 1966; 196: 1137-1139.

29. Wechsler BM, Karlson KE, Summers DN, Krasnow N, 
Garzon AA, Chait A. Pulmonary embolism: influence of cardiac hemodynamics and natural history on selection of patients for embolectomy and inferior cava ligation. Surgery 1969; 65: 182-190.

30. Nielsen HK, Husted SE, Krusel LR, Fasting H, Charles P, Hansen HH. Silent pulmonary embolism in patients with deep venous thrombosis. Incidence and fate in a randomised controlled trial of anticoagulation versus no anticoagulation. J Intern Med 1994; 235: 457-461.

31. Cullis JO, Chisholm M, Ackery DM. Unresolved pulmonary embolism: the role of fibrinolysis. Nucl Med Commun 1993; 14: 4-7.

32. Olman MA, Marsh JJ, Lang IM, Moser KM, Binder BR, Schleef RR. Endogenous fibrinolytic system in chronic large-vessel thromboembolic pulmonary hypertension. Circulation 1992; 86: 1241-1248.

33. Widimsky J. Acute pulmonary embolism and chronic thromboembolic pulmonary hypertension: is there a relationship? Eur Respir J 1991; 4: 137-140.

34. Widimsky J. Mechanisms in embolic pulmonary hypertension. In: Wagewoort CA, Desolin H, eds. Pulmonary circulation. Amsterdam, the Netherlands, Elsevier, 1989; pp. $75-86$.

35. Hall RJ, Sutton GC, Kerr IH. Long term prognosis of treated acute massive pulmonary embolism. Br Heart $J$ 1977; 39: 1128-1134

36. Benotti JR, Ockene IS, Alpert JS, Dalen JE. The clinical profile of unresolved pulmonary embolism. Chest 1983; 84: 669-677.

37. De Soyza NDB, Murphy ML. Persistant post-embolic pulmonary hypertension. Chest 1972; 62: 665-668.

38. Riedel M, Stanek V, Widimsky J. Long term follow-up of patients with pulmonary thromboembolism. Chest 1982; 81: 151-158.

39. Sharma GVRK, McIntyre KM, Sharma S, Sasahara AA. Clinical and hemodynamic correlates in pulmonary embolism. Clin Chest Med 1984; 5: 421-437.

40. Remy-Jardin M, Louvegny S, Remy J, et al. Acute central thromboembolic disease: posttherapeutic follow-up with spiral CT angiography. Radiology 1997; 203: 173-180.

41. Schuck JW, Walder JS, Kam TH, Thomas HM. Chronic persistent pulmonary embolism. Report of three cases. Am J Med 1980; 69: 790-794.

42. LaRue MJ, Muraugh RJ. Pulmonary thromboembolism in dogs: 47 cases (1986-1987). J Am Vet Med Assoc 1990; 197: 1368-1372.

43. Marshall R, Sabiston DC, Allison PR, et al. Immediate and late effects of pulmonary embolism by large thrombi in dogs. Thorax 1963; 18: 1-9.

44. Treolata SO, Johnson MS, Schwauwecker DS. Like cats and dogs: no perfect animal model for thrombolysis. Radiology 1997; 202: 31-32.

45. Moser KM, Cantor JP, Olman M, et al. Chronic pulmonary thromboembolism in dogs treated with tranexamic acid. Circulation 1991; 83: 1371-1379.

46. Moser KM, Auger WR, Fedullo PF. Chronic major-vessel thromboembolic pulmonary hypertension. Circulation 1990; 81: 1735-1743.

47. Falicov RE, Resnekov L, Petasnick J. Progressive pulmonary vascular obstruction and cor pulmonale due to repeated embolism from axillary vein thrombosis. Ann Intern Med 1970; 73: 429-431.

48. Garcin JM, Chanudet X, Brandstatt P, Dechaux JP, Clement R, Larroque P. Unusual complication of venous thrombosis of the upper limb. Revue de Pneumonologie Clinique 1993; 49: 147-152.

49. Ledesma CF, Campo Eschevarria JF, Zurbano GF, et al.
Pulmonary hypertension secondary to multiple pulmonary thromboembolisms due to thrombosis of the right subclavian vein. Annales de Medicina Interna 1994; 11 : 294-296.

50. Saviotti M. Chronic pulmonary hypertension caused by left axillary vein thrombosis. Report of a clinical case. Minerva Cardioangioligica 1994; 42: 191-194.

51. Quinson P, Lagable M, Mornex JF, Jegaden O, Thevenet F, Milon H. Phlebitis of the right upper limb and thromboembolic pulmonary hypertension. A propos of a case of heart-lung transplantation. Archives des Maladies du Coeur et des Vaisseaux 1994; 87: 287-290.

52. Gomes MR, Tamaso H, Nazarian GK, Bjarnason H, Dietz CA Jr, Hunter DW. Upper-extremity deep vein thrombosis and chronic pulmonary embolism resulting in pulmonary artery hypertension. AJR 1998; 170: 1532-1534.

53. Nelson JR, Smith JR. The pathologic physiology of pulmonary embolism. A physiologic discussion of the vascular reactions following pulmonary arterial obstruction by emboli of varying siz. Am Heart $J$ 1959; 58: $916-$ 933.

54. Steinberg B, Mundy CS. Experimental pulmonary embolism and infarction. Arch Pathol 1936; 22: 529.

55. Downing SE, Vidone RA. Pulmonary vascular responses to embolization with autologous thrombi. Surg Gynecol Obstet 1967; 269-278.

56. Olman MA, Gan RZ, Yen RT, et al. Effect of chronic thromboembolism on the pulmonary artery pressure-flow relationship in dogs. J Appl Physiol 1994; 76: 875-881.

57. Butterworth AE, Thorne KJI. Eosinophils and parisitic diseases. In: Smith H, Cook RM, eds. The handbook of immunopharmacology. Immunopharmacology of eosinophils. London, UK, Academic Press Harcount Brace Jovanovich, 1994; pp. 119-150.

58. Radow SK, Nachamkin I, Morrow C, et al. Foreign body granulomatosis. Clinical and immunologic findings. $\mathrm{Am}$ Rev Respir Dis 1983; 127: 575-580.

59. Winterbauer RH, Efenbein IB, Ball WC. Incidence and clinical significance of tumor embolization to the lungs. Am J Med 1968; 45: 271-290.

60. Veinot JP, Ford SE, Price RG. Subacute cor pulmonale due to tumor embolization. Arch Pathol Lab Med 1992; 116: 131-134.

61. Beech DJ, Putnam JB, Pollock RE. Treatment of the patient with lung metastases. Curr Prob Surg 1996; 33: 910-913.

62. Akiba Y, Nakano H, Osanai S, Matsumoto H, Kikuchi K. Role of nitric oxide in vasoreactivity caused by experimental pulmonary microembolism. Nippon Kyobu Geka Gakkai Zasshi 1995, 33: 1408-1414.

63. Rich S, Levitsky S, Brundage BH. Pulmonary hypertension from chronic pulmonary thromboembolism. Ann Intern Med 1988; 108: 425-434.

64. Neumann RD, Sostman HD, Gottschalk A. Current status of ventilation-perfusion imaging. Semin Nucl Med 1980; X: 198-237.

65. Abraham P, Carter D, Millot JR, Leftheriotis G, Pidhorz L, Saumet JL. Prolonged asymptomatic micro-embolism after hip or knee arthroplasty. J Bone Joint Surg Br 1997; 79: 269-272.

66. Olsen EGF. Repeated pulmonary thromboembolism in rabbits. Lab Invest 1975; 32: 323-329.

67. Schneider J, Seidl I, Weihe WH, Hess OM, Krayenbuhl HP. Massive pulmonary embolism in dogs without pulmonary hypertension. Res Exp Med 1980; 177: 43-52.

68. Sato K, Webb S, Tucker A, et al. Factors influencing the 
idiopathic development of pulmonary hypertension in the fawn hooded rat. Am Rev Respir Dis 1992; 145: 793-797.

69. Fedde MR, Wideman RF Jr. Blood viscosity in broilers: influence on pulmonary hypertension syndrome. Poult Sci 1996; 75: 1261-1267.

70. Enkvetchakul B, Beasley HJ, Bottje W. Pulmonary arteriole hypertrophy in broilers with pulmonary hypertension syndrome (ascites). Poult Sci 1995; 74: 1677-1682.

71. Pringel JK, Bright JM, Duncan RB Jr, Kerr L, Linnarbary $\mathrm{RD}$, Tarruer MP. Pulmonary hypertension in a group of dairy calves. J Am Vet Med Assoc 1991; 198: 857-861.

72. Bisgard GE. Pulmonary hypertension in cattle. $A d v$ Vet Sci Comp Med 1977; 21: 151-172.

73. Berg R, Pehlemann K. Anatomic studies of the pulmonary hypertension syndrome in the domestic pig. Anat Histol Embryol 1987; 16: 265-270.

74. Gelberg HB, Smetzer DL, Forman JH. Pulmonary hypertension as a cause of atrial fibrillation in young horses: four cases (1980-1989). J Am Vet Med Assoc 1991; 198: 679-682.

75. Egermayer P, Town GI, Peacock AJ. The role of serotonin in the pathophysiology of acute and chronic pulmonary hypertension. Thorax 1999; 54: 161-168.

76. Fadel E, Riou JY, Mazamanian M, et al. Pulmonary thromboendarterectomy for chronic thromboembolic obstruction of the pulmonary artery in piglets. $J$ Thorac Cardiovasc Surg 1999; 117: 787-793.

77. Lang IM, Klepetko W, Pabinger I. No increased prevalence of Factor $\mathrm{V}$ Leiden mutation in chronic major vessel thromboembolic hypertension (CTEPH). Thromb Haemost 1996; 76: 476-477.

78. Auger WR, Permpikul P, Moser KM. Lupus anticoagulant, heparin use, and thrombocytopenia in patients with chronic thromboembolic hypertension: a preliminary report. Am J Med 1995; 99: 392-396.

79. Azarian R, Brenot F, Sitbon O, et al. Pulmonary arterial hypertension of chronic thrombo-embolic origin, 70 patients. Presse Med 1994; 23: 1017-1022.

80. De Clerck LS, Michielson PP, Ramael MR, et al. Portal and pulmonary vessel thrombosis associated with systemic lupus erythematosus and anticardiolipin antibodies. J Rheumatol 1991; 18: 1919-1921.

81. Marz W, Trommlitz M, Scharrer I, Gross W. Apolipoprotein (a) concentrations are not related to the risk of venous thrombosis. Blood Coagul Fibrinolysis 1991; 2: 595-599.

82. Ignatescu M, Kostner K, Zorn G, et al. Plasma Lp(a) levels are increased in patients with chronic thromboembolic pulmonary hypertension. Thromb Haemostas 1998; 80: 231-232.

83. Schafer AI, Kroll MH. Non atheromatous arterial thrombosis. Annu Rev Med 1993; 44: 155-170.

84. Sompradeek S, Fedullo PF, Le DT. Congenital and acquired thrombophilias in patients with chronic thromboembolic pulmonary hypertension. Am J Respir Crit Care Med 1999; 159: A358.

85. Peacock AJ. Primary pulmonary hyptertension. Thorax 1999; 54: 1107-1118

86. Moser KM, Bloor CM. Pulmonary vascular lesions occurring in patients with chronic major vessel thromboembolic pulmonary hypertension. Chest 1993; 103: 685-692.

87. Egermayer P. Follow-up for death or recurrence is not a reliable way of assessing the accuracy of diagnostic tests for thromboembolic disease. Chest 1997; 111: 1410-1413.

88. Henry JW, Relyea B, Stein PD. Continuing risk of thromboemboli among patients with normal pulmonary angiograms. Chest 1995; 107: 1375-1378.
89. Bergqvist D. The role of vena caval interruption in patients with venous thromboembolism. Prog Cardiovasc Dis 1994; XXXVII: 25-37.

90. Ballew KA, Philbrick JT, Becker DM. Vena caval filter devices. Clin Chest Med 1995; 16: 295-305.

91. Michel RP, Hu F, Meyrick BO. Myoendothelial junctional complexes in postobstructive pulmonary vasculopathy: a quantitative electron microscope study. Experim Lung Res 1995; 21: 437-452.

92. Hirsch AM, Moser KM, Auger WR, Channick RN, Fedullo PF. Unilateral pulmonary artery thrombotic occlusion. Is distal arteriopathy a consequence? Am Rev Respir Crit Care Med 1996; 154: 491-496.

93. Shure D. Thrombendartectomy: some unanswered questions. Ann Thorac Surg 1996; 62: 1253-1254.

94. Weis M, von Scheidt W. Cardiac allograft vasculopathy. A review. Circulation 1997; 96: 2069-2077.

95. Sevitt S, Walton KW. Atherosclerotic lesions from the reduction of pulmonary emboli. Atherosclerosis 1986; 59: 173-185.

96. Uchida Y, Oshima T, Hirose J, Sasaki T, Morizuki S, Morita T. Angioscopic detection of residual pulmonary thrombi in the differential diagnosis of pulmonary embolism. Am Heart $J$ 1995; 130: 854-859.

97. Kodama I, Sugada Y, Shimizu T, Hoshi S. Proceedings: pulmonary hypertension associated with marked pulmonary arteriosclerosis and thrombus formation. Japn Circ J 1975; 39: 874.

98. Yamamoto M. Pathology of experimental pulmonary bone marrow embolism. II Postembolic pulmonary arteriosclerosis and pulmonary hypertension in rabbits receiving an intravenous infusion of allogeneic bone marrow. Acta Pathol Japn 1987; 37: 705-724.

99. Moore GW, Smith RRL, Hutchins GM. Pulmonary artery atherosclerosis. Correlation with systemic atherosclerosis and hypertensive pulmonary vascular disease. Arch Pathol Lab Med 1982; 106: 378-380.

100. Sofia M, Faraone S, Alifano M, et al. Endothelin abnormalities in patients with pulmonary embolism. Chest 1997; 111: 544-549.

101. Robin ED, Cross CE, Kroetz F, Totten RS, Bron K. Pulmonary hypertension and unilateral pleural constriction with speculation on pulmonary vasoconstrictive substance. Arch Intern Med 1966; 118: 391-400.

102. Ross R, Wight TN, Strandness E, Thiele B. Human atherosclerosis. 1 Cell constitution and characteristics of advanced lesions of the superficial femoral artery. Am J Pathol 1984; 114: 79-93.

103. Jamieson SW. Pulmonary thrombendartectomy. Heart 1998; 79: 118-120.

104. Moser KM, Fedullor PF. Acute and chronic pulmonary thromboembolism. In: Peacock AJ, (ed) Pulmonary Circulation. A Handbook for Clinicians. London, UK, Chapman \& Hall Medical, 1996; pp. 391-422.

105. Chouat A, Weitzenblum E, Higgenbottam T. The role of thrombosis in severe pulmonary hypertension. Eur Respir $J$ 1996; 9: 356-363.

106. Calverly PMA, Howatson R, Flenley DC. Clinicopathological correlations in cor pulmonale. Thorax 1992; 47: 494-498.

107. Presti B, Berthrong M, Sherwin RM. Chronic thrombosis of major pulmonary arteries. Hum Pathol 1990; 21: 601606.

108. Eisenberg PR, Lucore C, Kaufman L, Sobel BE, Jaffe AS, Rich S. Fibrinopeptide A levels indicative of pulmonary vascular thrombosis in patients with primary pulmonary hypertension. Circulation 1990; 82: 841-847. 
109. Symbas PN, Jacobs WF, Schlant RC. Chronic pulmonary artery embolization or thrombosis. Am J Cardiol 1971; 28: $342-347$.

110. Schulman LL, Grossman BA, Owen J. Platelet activation and fibrinopeptide formation in pulmonary hypertension. Chest 1993; 104: 1690-1693.

111. Moser KM, Fedullo PF, Finkbeiner DC. Do patients with primary pulmonary hypertension develop extensive central thrombi? Circulation 1995; 91: 741-745.

112. Fuster V, Steele PM, Edwards WD, Gersh BJ, McGoon MD, Frye RL. Primary pulmonary hypertension: natural history and the importance of thrombosis. Circulation 1984; 70: 580-587.

113. Moser KM, Olson LK, Schlussberg M, Daily PO, Dembitsky WP. Chronic thromboembolic occlusion in the adult can mimic pulmonary artery agenesis. Chest 1989; 95: 503508.

114. Kerr KM, Auger WR, Fedullo PF. Large vessel pulmonary arteritis mimicking chronic thromboembolic disease. Am J Respir Crit Care Med 1995; 152: 367-373.

115. Samuels N, Berkman N, Milgalter E, Bar-Zine J, Amir G, Kramer MR. Pulmonary hypertension secondary to neurofibromatosis: intimal fibrosis versus thromboembolism. Thorax 1999; 54: 858-859.

116. Berry DF, Buccigrosst D, Peabody J, Peterson K, Moser KM. Pulmonary vascular occlusion and fibrosing mediastinitis. Chest 1986; 2: 296-301.

117. Datz FL. Ventilation-perfusion mismatch: Lung imaging. Semin Nucl Med 1980; X: 193.

118. Tardivon AA, Musset D, Maitre S, et al. Role of CT in chronic pulmonary embolism: comparison with pulmonary angiography. JComput Assist Tomo 1993; 17:345-351.

119. Frank H, Mlczoch J, Huber K, Shuster E, Gurtner HP, Kneussel M. The effect of anticoagulant therapy in primary and anorectic drug-induced pulmonary hypertension. Chest 1997; 112: 714-721. 